\title{
Photocatalysis and Photoelectrochemical Properties of Tungsten Trioxide Nanostructured Films
}

\author{
Chin Wei Lai \\ Nanotechnology \& Catalysis Research Centre (NANOCAT), Institute of Postgraduate Studies (IPS), University of Malaya, \\ 3rd Floor, Block A, 50603 Kuala Lumpur, Malaysia \\ Correspondence should be addressed to Chin Wei Lai; cwlai@um.edu.my
}

Received 13 January 2014; Accepted 4 March 2014; Published 20 March 2014

Academic Editors: J. Shi and H. Zhou

Copyright (C) 2014 Chin Wei Lai. This is an open access article distributed under the Creative Commons Attribution License, which permits unrestricted use, distribution, and reproduction in any medium, provided the original work is properly cited.

Tungsten trioxide $\left(\mathrm{WO}_{3}\right)$ possesses a small band gap energy of $2.4-2.8 \mathrm{eV}$ and is responsive to both ultraviolet and visible light irradiation including strong absorption of the solar spectrum and stable physicochemical properties. Thus, controlled growth of one-dimensional (1D) $\mathrm{WO}_{3}$ nanotubular structures with desired length, diameter, and wall thickness has gained significant interest. In the present study, $1 \mathrm{D} \mathrm{WO}_{3}$ nanotubes were successfully synthesized via electrochemical anodization of tungsten (W) foil in an electrolyte composed of $1 \mathrm{M}$ of sodium sulphate $\left(\mathrm{Na}_{2} \mathrm{SO}_{4}\right)$ and ammonium fluoride $\left(\mathrm{NH}_{4} \mathrm{~F}\right)$. The influence of $\mathrm{NH}_{4} \mathrm{~F}$ content on the formation mechanism of anodic $\mathrm{WO}_{3}$ nanotubular structure was investigated in detail. An optimization of fluoride ions played a critical role in controlling the chemical dissolution reaction in the interface of $\mathrm{W} / \mathrm{WO}_{3}$. Based on the results obtained, a minimum of $0.7 \mathrm{wt} \%$ of $\mathrm{NH}_{4} \mathrm{~F}$ content was required for completing transformation from $\mathrm{W}$ foil to $\mathrm{WO}_{3}$ nanotubular structure with an average diameter of $85 \mathrm{~nm}$ and length of $250 \mathrm{~nm}$ within $15 \mathrm{~min}$ of anodization time. In this case, high aspect ratio of $\mathrm{WO}_{3}$ nanotubular structure is preferred because larger active surface area will be provided for better photocatalytic and photoelectrochemical (PEC) reactions.

\section{Introduction}

Design and controlled growth of nanostructure semiconductor assemblies has gained significant attention in recent years due to the scientific interests and potential applications $[1,2]$. In this manner, $\mathrm{WO}_{3}$ is one of the famous electrochromic inorganic materials since Deb's discovery in 1969 [3]. $\mathrm{WO}_{3}$ film exhibits a broad range of functional properties, such as small band gap energy $(2.4-2.8 \mathrm{eV})$, deeper valence band $(+3.1 \mathrm{eV})$, stable physicochemical properties, and strong photocorrosion stability in aqueous solution [410]. The characteristics of $\mathrm{WO}_{3}$ film make them suitable for electrochromic layers in a smart window [11]. Many studies pertaining to $\mathrm{WO}_{3}$ nanostructures are mainly aimed at the formation of high active surface area in view of their use in electrochromic applications $[9,10]$. However, several studies have reported that growth of well-aligned and uniformity of anodic $\mathrm{WO}_{3}$ nanotubular structure was a difficult task and most of the studies were only able to grow anodic $\mathrm{WO}_{3}$ into nanoporous instead of nanotubular structure $[7-10,12,13]$. In the present study, we describe the synthesis of well-aligned anodic $\mathrm{WO}_{3}$ nanotubes using electrochemical anodization technique in a fluorinated-based electrolyte. To the best of our knowledge, literatures on optimization of the geometrical features of regular anodic $\mathrm{WO}_{3}$ nanotubular structures are still lacking. Thus, such mechanistic studies and understanding are very important to tailor the desired length, pore size, and wall thickness of ordered $\mathrm{WO}_{3}$ nanotubular structures for high surface area to volume ratio. In this study, a comprehensive experiment was conducted to control the one-dimensional nanostructure of anodic $\mathrm{WO}_{3}$ using electrochemical anodization to achieve effective photocatalytic degradation of $\mathrm{MO}$ dye and $\mathrm{H}_{2}$ gas generation via PEC water splitting process.

\section{Experimental Procedure}

The high purity (99.95\% purity with $0.1 \mathrm{~mm}$ in thickness) tungsten (W) foils from Alfa Aesar USA were used in 
this study. Prior to anodization, W foils were degreased in ultrasonic bath containing ethanol for 30 minutes. The foils were then rinsed in deionized water and dried in nitrogen stream. Then, anodization was performed in a two-electrode configuration bath with $\mathrm{W}$ foil served as the anode and the platinum electrode served as the counter electrode. The electrolyte is composed of $100 \mathrm{~mL}$ of $1 \mathrm{M}$ of sodium sulfate $\left(\mathrm{Na}_{2} \mathrm{SO}_{4}\right.$, Merck, USA) solution with ammonium fluoride $\left(\mathrm{NH}_{4} \mathrm{~F}\right.$, Merck, USA) at $40 \mathrm{~V}$ with sweep rate of $1 \mathrm{~V} / \mathrm{s}$. In the present study, different content of $\mathrm{NH}_{4} \mathrm{~F}(0.3,0.5$, and $0.7 \mathrm{wt} \%$ ) will be added into $1 \mathrm{M} \mathrm{Na} \mathrm{SO}_{4}$ solution for several anodization duration $(15,30$, and $60 \mathrm{~min})$ in order to investigate the formation of anodic $\mathrm{WO}_{3}$ nanotubular structures. As-anodized anodic $\mathrm{WO}_{3}$ samples were cleaned using acetone (J.T. Baker, Nederland) and dried in nitrogen stream after anodization process. The morphologies of anodic $\mathrm{WO}_{3}$ nanostructures were observed by field emission scanning electron microscopy (FESEM), using a FEI Quanta 200 (FESEM model, USA) at a working distance of around $1 \mathrm{~mm}$. The cross-sectional observation was carried out on mechanically bent samples to get the thickness of the oxide layer. The chemical stoichiometry of the sample was characterized using energy dispersive X-ray (EDX) analysis, which is equipped in the FESEM. In order to assess the photocatalytic performance of the anodic $\mathrm{WO}_{3}$ nanostructure formed, anodized $\mathrm{W}$ foil of $25 \mathrm{~mm} \times 25 \mathrm{~mm}$ was prepared and placed in $200 \mathrm{~mL}$ of $30 \mathrm{ppm}$ MO dye in a customized photoreactor made of quartz glass. Two different surface morphologies of anodic $\mathrm{WO}_{3}$ nanostructure were selected for MO dye degradation purpose (e.g., oxide layer and nanotubular structure). In the present study, both samples were left in the photoreactor for $30 \mathrm{~min}$ in a dark environment to achieve adsorption/desorption equilibrium. Then, both samples were photo-irradiated at room temperature by using a $150 \mathrm{~W}$ Xenon solar simulator (Zolix LSP-X150) with intensity of $800 \mathrm{~W} / \mathrm{m}^{2}$. A $5 \mathrm{~mL}$ solution was removed at an interval of $1 \mathrm{~h}$ from the photoreactor, and concentration of the solution was measured using a UV spectrophotometer (PerkinElmer Lambda 35). Next, the photoelectrochemical properties of the selected samples were further characterized using a three-electrode water splitting cell, with $\mathrm{WO}_{3}$ nanotubes as the working electrode, platinum rod as the counter electrode, and saturated calomel electrode (SCE) as the reference electrode. The bath with electrolyte composed of $0.5 \mathrm{M}$ sulfuric acid aqueous solution was selected in this experimental work. The $\mathrm{H}_{2}$ gas generated at platinum rod was collected using the water displacement technique. As the $\mathrm{H}_{2}$ gas was produced in counter electrode in water splitting chamber, it was bubbling up into inverted burette. The volume of $\mathrm{H}_{2}$ gas was determined by reading the gas level on the side of burette.

\section{Results and Discussion}

In the present study, the effect of fluoride content and anodization time on the morphology of anodic $\mathrm{WO}_{3}$ layer was investigated. Figure 1 to Figure 3 showed the surface morphologies of anodic $\mathrm{WO}_{3}$ layer in different fluoride content electrolyte from $15 \mathrm{~min}$ up to $60 \mathrm{~min}$ of anodization time. As shown from the FESEM images, the appearance of anodic $\mathrm{WO}_{3}$ layer was strongly dependent on the fluoride content and anodization times. Then, the EDX analysis was employed to investigate the composition of element of $\mathrm{W}$ and $\mathrm{O}$ from the anodic $\mathrm{WO}_{3}$ layer. Based on the results obtained, the atomic percentage of $\mathrm{W}$ element was about 55 at $\%$ and $\mathrm{O}$ element was about $45 \%$ at\%. During electrochemical anodization, fluoride content played an important role in controlling the chemical dissolution rate at the interface of $\mathrm{W} / \mathrm{WO}_{3}$ [14]. Figure 1 exhibited variations of $\mathrm{WO}_{3}$ surface morphology under low $0.3 \mathrm{wt} \%$ fluoride content electrolyte for different anodization times. It could be observed that formation of oxide layer on $\mathrm{W}$ foil was incomplete at 15 min of anodization time (Figure 1(a)). Interestingly, only thin compact oxide layer with randomly pits was formed after prolonging the anodization time to $30 \mathrm{~min}$ and $60 \mathrm{~min}$ (Figures 1(b) and 1(c)). The resultant thickness of oxide layer was approximately $100 \mathrm{~nm}$. These results indicated that low fluoride concentration was insufficient in forming the deep and large pore size on the oxide layer due to the inactive chemical dissolution reaction [15]. In this case, oxygen ions within the electrolyte through the $\mathrm{W}$ surface towards the $\mathrm{W} / \mathrm{WO}_{3}$ interface induce further growth of the oxide layer under applied potential. The high electric field across the oxide layer of $\mathrm{WO}_{3}$ and subsequently induce the polarization of $\mathrm{W}-\mathrm{O}$ bonding, which is able to transfer the $\mathrm{W}^{6+}$ ions from the pores and leave behind random pits $[14,15]$. By further increasing the content of fluoride to $0.5 \mathrm{wt} \%$, the irregular anodic $\mathrm{WO}_{3}$ nanoporous structure with thickness of approximately $200 \mathrm{~nm}$ could be observed from Figures 2(a) to 2(c). However, it could be noticed that the pore diameter on the oxide layer was increasing up to $70 \mathrm{~nm}$ when prolonging the anodization time to $60 \mathrm{~min}$. The uniform anodic nanoporous $\mathrm{WO}_{3}$ layer could be achieved in $1 \mathrm{M} \mathrm{Na} \mathrm{SO}_{4}$ electrolyte composed of $0.5 \mathrm{wt} \%$ fluorides content. When the fluoride content was further increased to $0.7 \mathrm{wt} \%$, a hollow cylinder oxide nanostructure was observed as shown in Figure 3(a), which indicated that the amount of fluoride in the electrolyte was sufficient to increase the chemical dissolution rate. This condition led to further acidification reactions to develop the nanoporous structure into nanotubular structure [16-18]. In this case, tungsten fluoro-complex ions within the electrolyte playing an important role in inducing chemical dissolution to enlarge and deepen pores and eventually transforming to nanotubular structure [14]. It is noteworthy to mention that the $\mathrm{WO}_{3}$ nanotubes with diameters of approximately $85 \mathrm{~nm}$ and lengths of $250 \mathrm{~nm}$ were successfully formed when the fluoride content was increased to $0.7 \mathrm{wt} \%$. However, nanotubular structure disappeared when further the anodization time increased to $30 \mathrm{~min}$ and $60 \mathrm{~min}$ and eventually resulted in irregular nanoporous structure (Figures 3(b) and $3(\mathrm{c})$ ). The reason might be attributed to the excessive chemical etching on the wall surface of nanotubes during the chemical dissolution reactions. Thus, optimization of fluoride content identified in our electrolyte was $0.5 \mathrm{wt} \%$ in order to grow the well-aligned one-dimensional $\mathrm{WO}_{3}$ nanotubes for $15 \mathrm{~min}$ electrochemical anodization duration. Figure 4 presented a simple schematic illustration of formation of 


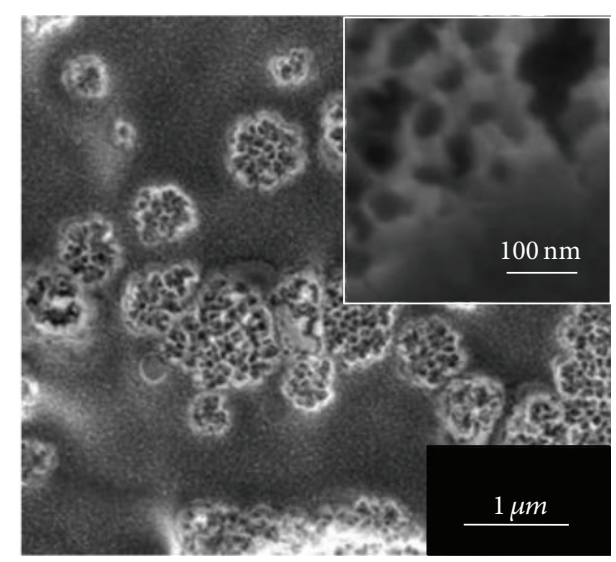

(a)

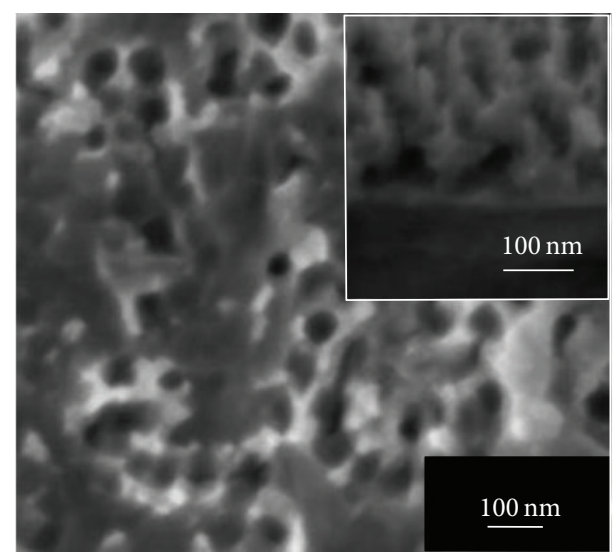

(b)

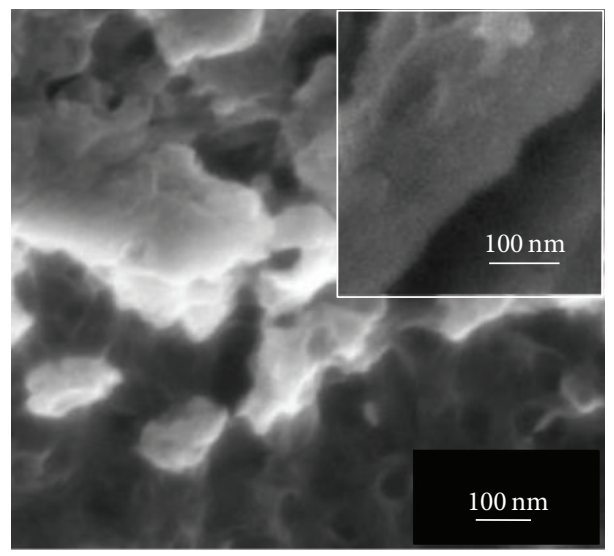

(c)

FIgURE 1: FESEM images of anodic $\mathrm{WO}_{3}$ nanostructures obtained in $1 \mathrm{M} \mathrm{Na} \mathrm{SO}_{4}$ electrolyte containing 0.3 wt $\%$ NH $\mathrm{F}_{4} \mathrm{~F}$ for different anodization times at $40 \mathrm{~V}$ : (a) $15 \mathrm{~min}$, (b) $30 \mathrm{~min}$, and (c) $60 \mathrm{~min}$. Insets show the cross-sectional view of anodic oxide layers.

anodic $\mathrm{WO}_{3}$ nanostructured film during electrochemical anodization stage in the presence of insufficient and adequate fluoride content.

The photocatalytic removal ability of the selected sample of anodic $\mathrm{WO}_{3}$ oxide layer was compared with that of the anodic $\mathrm{WO}_{3}$ nanotubular structure by exposing the samples to $\mathrm{MO}$ dye under solar illumination. The initial MO dye concentration in the solution was fixed at $30 \mathrm{ppm}$. The changes in MO dye concentration were investigated within 5 hours and the result was shown in Figure 5. The degradation rates of $\mathrm{MO}$ dye concentration for sample "anodic $\mathrm{WO}_{3}$ oxide layer" and sample "anodic $\mathrm{WO}_{3}$ nanotubular structure" was decreased from $30 \mathrm{ppm}$ to $13.5 \mathrm{ppm}$ and $8.5 \mathrm{ppm}$, respectively. When anodic $\mathrm{WO}_{3}$ nanotubular structure exposed to the $h v$ illumination that solar photonic energy is higher than its band gap energy $(2.4-2.8 \mathrm{eV})$, the anodic $\mathrm{WO}_{3}$ itself will generate pairs of photo-induced electrons $\left(\mathrm{e}^{-}\right)$and holes $\left(\mathrm{h}^{+}\right)$. In this manner, the $\mathrm{e}^{-}$and oxygen molecule $\left(\mathrm{O}_{2}\right)$ will combine to form super oxide anion $\left(\mathrm{O}_{2}{ }^{--}\right)$, whereas the $\mathrm{h}^{+}$of anodic $\mathrm{WO}_{3}$ and water molecule $\left(\mathrm{H}_{2} \mathrm{O}\right)$ will generate hydroxyl radical $\left({ }^{\circ} \mathrm{OH}\right)$. These powerful oxidizing agents $\left({ }^{\circ} \mathrm{OH}\right.$ and $\mathrm{O}_{2}{ }^{--}$) will then decompose the $\mathrm{MO}$ dye (organic dye) into $\mathrm{CO}_{2}$ and $\mathrm{H}_{2} \mathrm{O}$. This cycle will continue when the $h v$ illumination is available. A simple schematic illustration of basic principal in photocatalytic degradation of $\mathrm{MO}$ dye is shown in Figure 6. In theoretical perspectives, the photocatalytic degradation performance of anodic $\mathrm{WO}_{3}$ can be related on the ability to generate pairs of charge carriers, which will release powerful oxidizing agents $\left({ }^{\circ} \mathrm{OH}\right.$ and $\mathrm{O}_{2}{ }^{--}$) that are able to undergo the secondary reactions. In other words, anodic $\mathrm{WO}_{3}$ nanotubular structure with larger surface area of active reaction sites (inner and outer wall surface of nanotubes) has better photon absorption under $h v$ illumination. The distance of light scattering inside the nanotubes extends and provides more photon absorption to trigger the photocatalytic degradation reaction.

On the other hand, the evolution rate of $\mathrm{H}_{2}$ gas generated from the photoelectrochemical (PEC) water-splitting process under solar illumination was measured. The $\mathrm{H}_{2}$ evolution as a function of time is shown in Figure $7 . \mathrm{H}_{2}$ generation rate from water splitting reaction increased linearly with increasing exposure time. The sample (anodic $\mathrm{WO}_{3}$ nanotubular structure) achieved a maximum evolution of approximately $1 \mathrm{~mL} / \mathrm{cm}^{2}$ within 1 hour, which is relatively higher compared with the anodic $\mathrm{WO}_{3}$ oxide layer. The $\mathrm{H}_{2}$ production completely stopped after the termination 


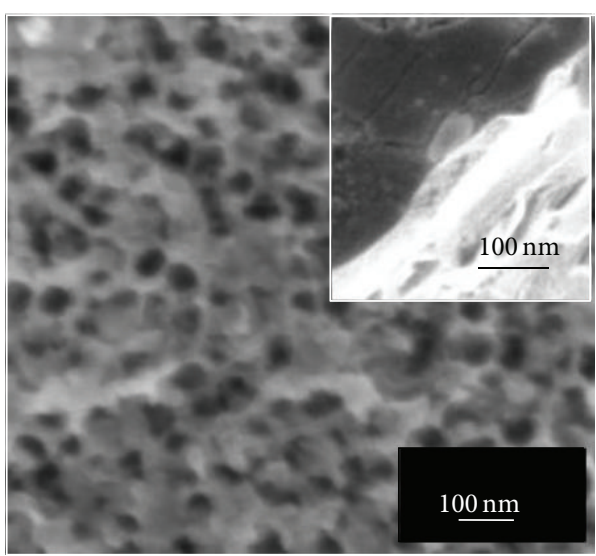

(a)

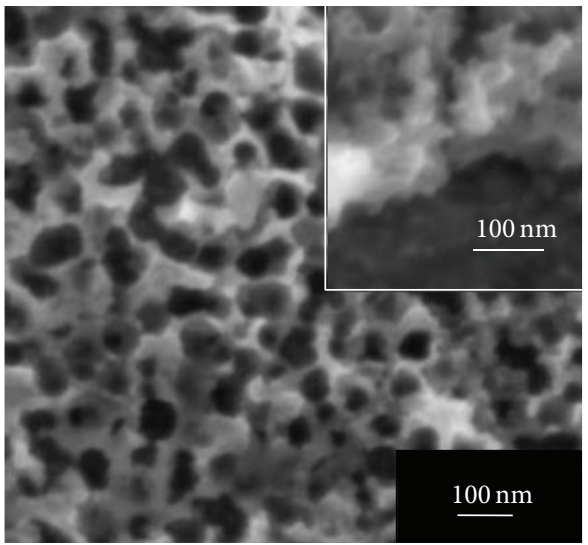

(b)

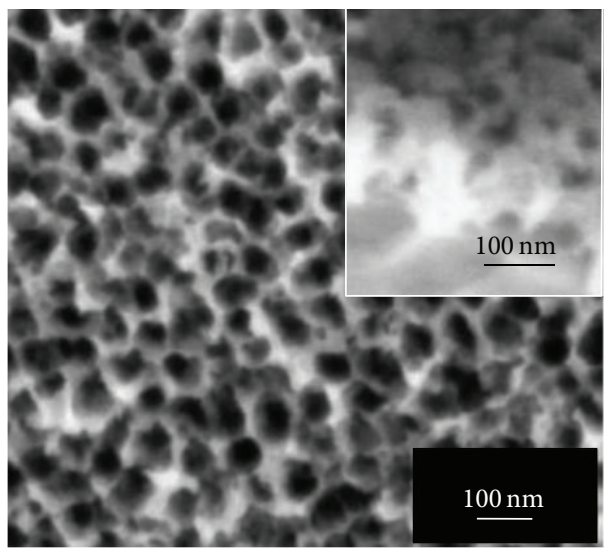

(c)

FIGURE 2: FESEM images of anodic $\mathrm{WO}_{3}$ nanostructures obtained in $1 \mathrm{M} \mathrm{Na}_{2} \mathrm{SO}_{4}$ electrolyte containing $0.5 \mathrm{wt} \% \mathrm{NH}_{4} \mathrm{~F}$ for different anodization times at $40 \mathrm{~V}$ : (a) $15 \mathrm{~min}$, (b) $30 \mathrm{~min}$, and (c) $60 \mathrm{~min}$. Insets show the cross-sectional view of anodic oxide layers.

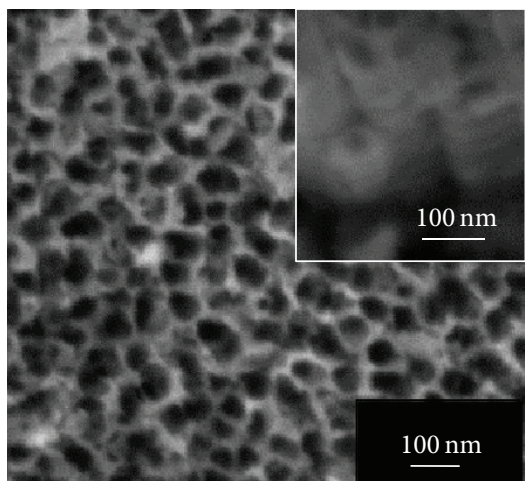

(a)

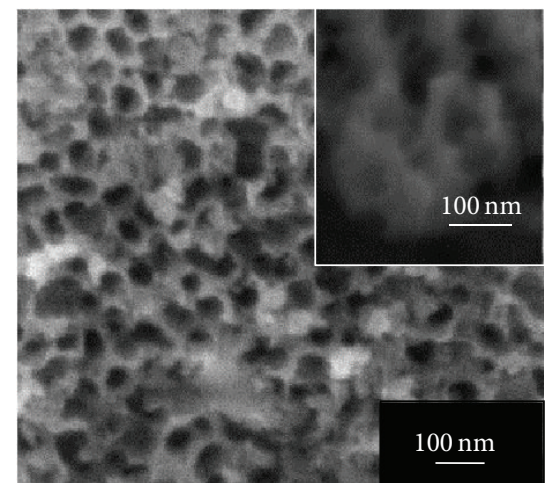

(b)

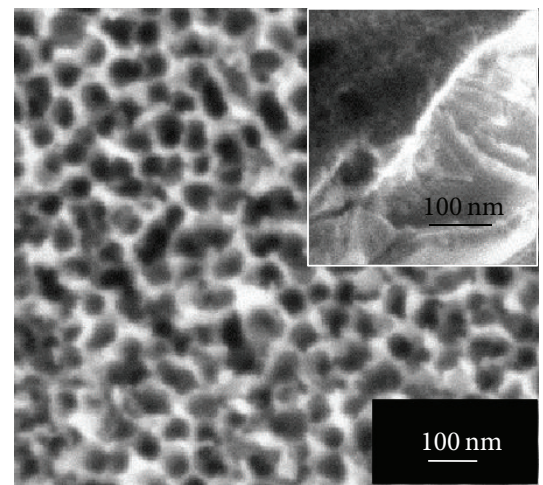

(c)

Figure 3: FESEM images of anodic $\mathrm{WO}_{3}$ nanostructures obtained in $1 \mathrm{M} \mathrm{Na}_{2} \mathrm{SO}_{4}$ electrolyte containing $0.7 \mathrm{wt} \% \mathrm{NH}_{4} \mathrm{~F}$ for different anodization times at $40 \mathrm{~V}$ : (a) $15 \mathrm{~min}$, (b) $30 \mathrm{~min}$, and (c) $60 \mathrm{~min}$. Insets show the cross-sectional view of anodic oxide layers.

of $h v$ illumination. This observation clearly shows that $\mathrm{H}_{2}$ is only produced photocatalytically. A constant production rate of $\mathrm{H}_{2}$ gas could be observed in the present study. In theoretical perspectives, PEC water splitting process is the general term for a chemical reaction in which water is separated into $\mathrm{O}_{2}$ and $\mathrm{H}_{2}$ using anodic $\mathrm{WO}_{3}$ film that catalyze the water splitting reaction. A basic schematic diagram of such overall water splitting reaction using a semiconductor photocatalyst is presented in Figure 8. The water splitting reaction can be summarized as follows: $2 \mathrm{H}_{2} \mathrm{O}(\mathrm{l}) \rightarrow$ 


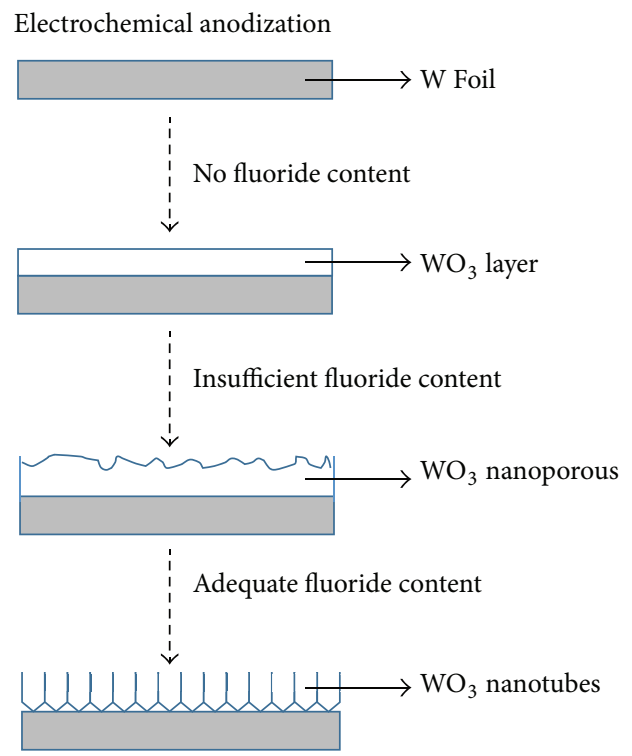

FIGURE 4: Schematic illustration of formation and mechanistic studies of anodic $\mathrm{WO}_{3}$ nanostructured film with and without fluoride content during electrochemical anodization stage.

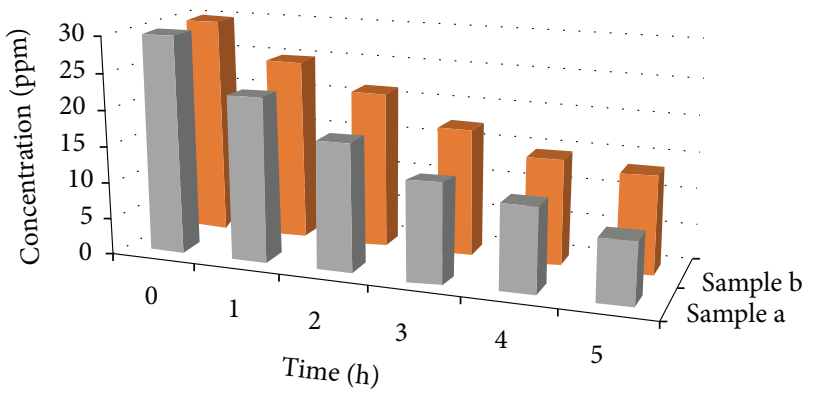

FIGURE 5: Photodegradation of $\mathrm{MO}$ dye: (a) anodic $\mathrm{WO}_{3}$ nanostructures obtained in $1 \mathrm{M} \mathrm{Na}_{2} \mathrm{SO}_{4}$ electrolyte containing $0.7 \mathrm{wt} \% \mathrm{NH}_{4} \mathrm{~F}$ for $15 \mathrm{~min}$ at $40 \mathrm{~V}$, (b) anodic $\mathrm{WO}_{3}$ nanostructures obtained in $1 \mathrm{M}$ $\mathrm{Na}_{2} \mathrm{SO}_{4}$ electrolyte containing $0.3 \mathrm{wt} \% \mathrm{NH}_{4} \mathrm{~F}$ for $15 \mathrm{~min}$ at $40 \mathrm{~V}$.

$\mathrm{O}_{2}(\mathrm{~g})+2 \mathrm{H}_{2}(\mathrm{~g})$. The overall water splitting reaction is considered as a thermodynamically uphill reaction with a large Gibbs free energy of $\Delta \mathrm{G}^{0}=+237.2 \mathrm{KJ} \mathrm{mol}^{-1}$. This reaction indicates that photon energy is required to overcome the large positive change in Gibbs free energy through PEC water splitting process $[19,20]$. The light-driven water splitting process is triggered when anodic $\mathrm{WO}_{3}$ film absorbs photons from $h v$ illumination with energies greater than its band gap energy. This light absorption generates negative $\mathrm{e}^{-}$in the conduction band and positive $\mathrm{h}^{+}$in the valence band. The $\mathrm{h}^{+}$performs work at the anodic $\mathrm{WO}_{3}$ electrolyte interface oxidizing water molecules to create $\mathrm{O}_{2}$ and $\mathrm{H}^{+}$ions within the electrolyte. Then, the $\mathrm{e}^{-}$will move through the external circuit to the platinum electrode (counter electrode) where they reduce $\mathrm{H}^{+}$ions creating $\mathrm{H}_{2}$ molecules due to the electric field or under external bias [20]. The PEC water splitting performance is consistent with the photocatalytic degradation. In summary, the self-organized $\mathrm{WO}_{3}$ nanotubular structure

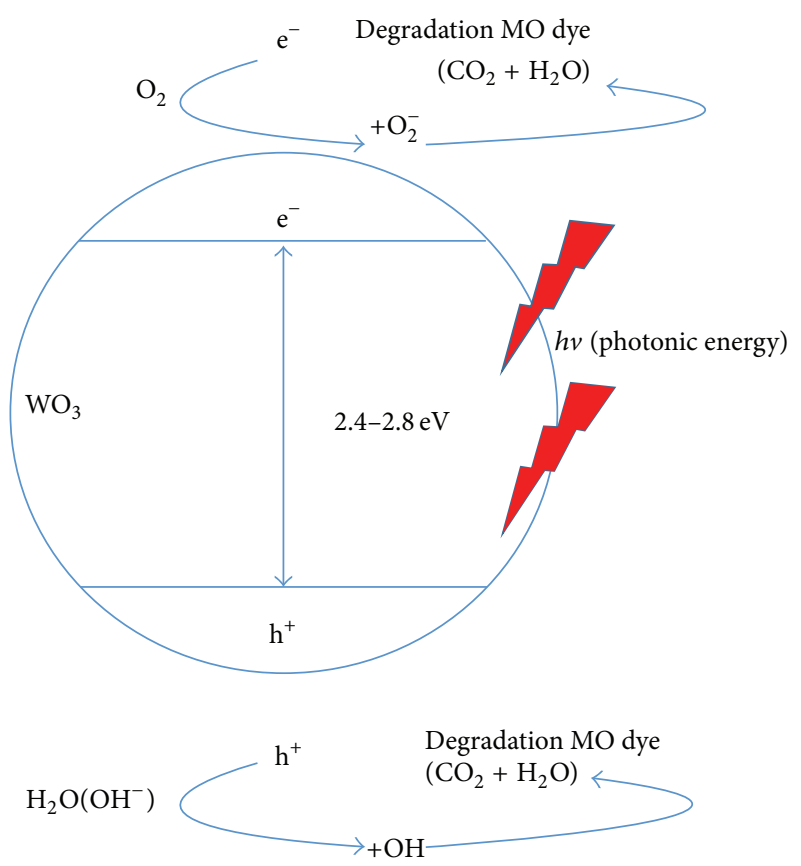

FIGURE 6: The overall mechanism of the photocatalytic degradation of $\mathrm{MO}$ dye using $\mathrm{WO}_{3}$ nanostructured film under solar illumination.

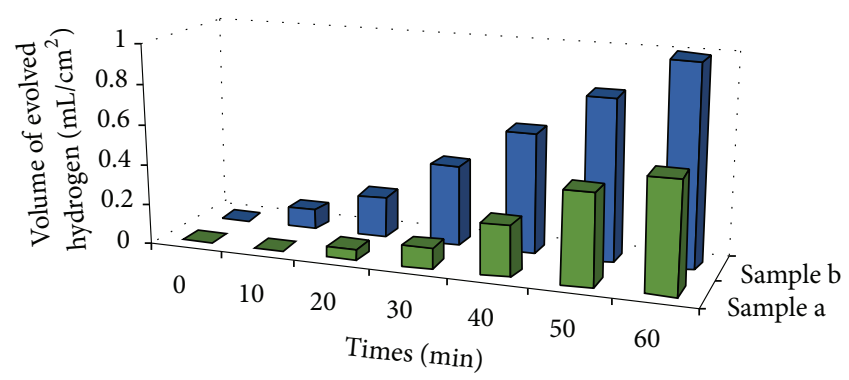

FIgURE 7: $\mathrm{H}_{2}$ evolution under solar illumination of (a) anodic $\mathrm{WO}_{3}$ nanostructures obtained in $1 \mathrm{M} \mathrm{Na}_{2} \mathrm{SO}_{4}$ electrolyte containing $0.3 \mathrm{wt} \% \mathrm{NH}_{4} \mathrm{~F}$ for $15 \mathrm{~min}$ at $40 \mathrm{~V}$ and (b) anodic $\mathrm{WO}_{3}$ nanostructures obtained in $1 \mathrm{M} \mathrm{Na}_{2} \mathrm{SO}_{4}$ electrolyte containing $0.7 \mathrm{wt} \% \mathrm{NH}_{4} \mathrm{~F}$ for $15 \mathrm{~min}$ at $40 \mathrm{~V}$.

has strong ability to release much more photo-induced $\mathrm{e}^{-} / \mathrm{h}^{+}$ pairs than that of compact layer structure. Thus, it is crucial to maximize the active surface area of photocatalyst (anodic $\mathrm{WO}_{3}$ ) for better photocatalytic and photoelectrochemical performance.

\section{Conclusion}

In conclusion, complete transformation of $\mathrm{W}$ foil to onedimensional $\mathrm{WO}_{3}$ nanotubes with an average diameter of $85 \mathrm{~nm}$ and length of $250 \mathrm{~nm}$ could be achieved within $15 \mathrm{~min}$ in an electrolyte composed of $1 \mathrm{M}$ of $\mathrm{Na}_{2} \mathrm{SO}_{4}$ and $0.7 \mathrm{wt} \%$ of $\mathrm{NH}_{4} \mathrm{~F}$. The main reason attributed to the sufficiency of tungsten fluoro-complex ions induced chemical dissolution to enlarge and deepen pores and eventually transform to nanotubes. The ability to grow large active surface area 


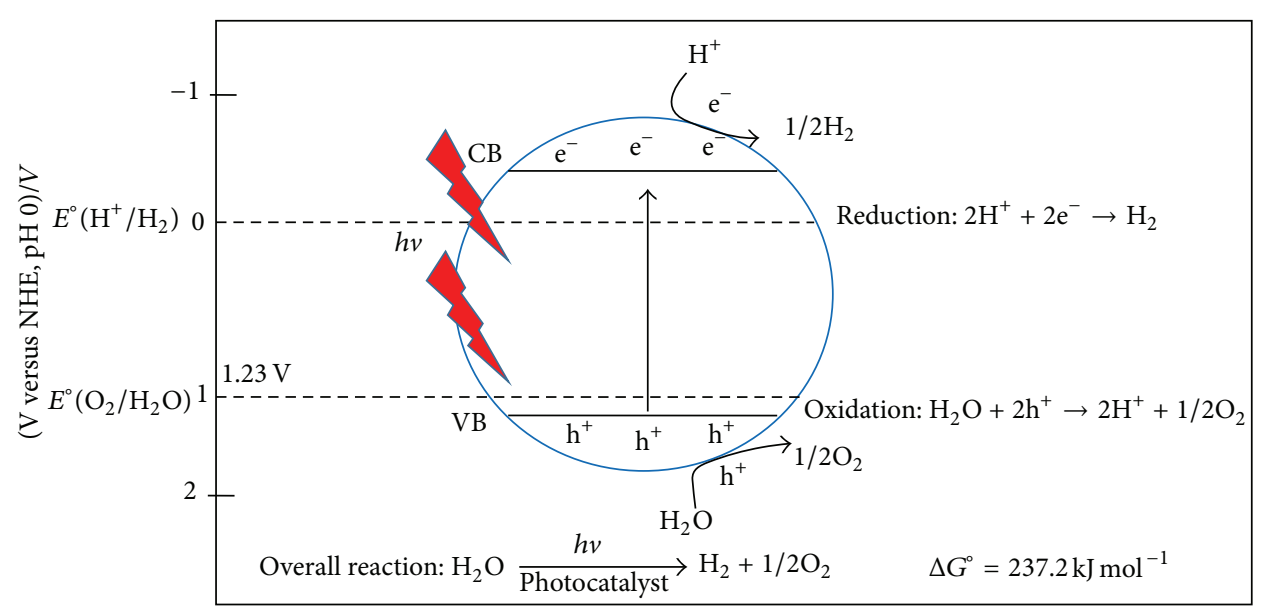

FIGURE 8: Basic principle of the overall water splitting for $\mathrm{H}_{2}$ generation using a $\mathrm{WO}_{3}$ nanostructured film.

of anodic $\mathrm{WO}_{3}$ nanostructures demonstrated a substantial enhancement in the degradation of $\mathrm{MO}$ dye and $\mathrm{H}_{2}$ generation via water splitting process, as compared to the anodic $\mathrm{WO}_{3}$ oxide layers.

\section{Conflict of Interests}

The author declares that there is no conflict of interests regarding the publication of this paper.

\section{Acknowledgments}

This research is supported by High Impact Research Chancellory Grant UM.C/625/1/HIR/228 (J55001-73873) from the University of Malaya. In addition, authors would like to thank University of Malaya for sponsoring this work under University of Malaya Research Grant (UMRG, RP022-2012D).

\section{References}

[1] C. A. Grimes, "Synthesis and application of highly ordered arrays of $\mathrm{TiO}_{2}$ nanotubes," Journal of Materials Chemistry, vol. 17, pp. 1451-1457, 2013.

[2] C. W. Lai and S. Sreekantan, "Preparation of hybrid $\mathrm{WO}_{3^{-}}$ $\mathrm{TiO}_{2}$ nanotube photoelectrodes using anodization and wet impregnation: improved water-splitting hydrogen generation performance," International Journal of Hydrogen Energy, vol. 38, no. 5, pp. 2156-2166, 2013.

[3] S. K. Deb, "A novel electrophotographic system," Applied Optics, vol. 8, no. 1, pp. 192-195, 1969.

[4] C. Trimble, M. DeVries, J. S. Hale, D. W. Thompson, T. E. Tiwald, and J. A. Woollam, "Infrared emittance modulation devices using electrochromic crystalline tungsten oxide, polymer conductor, and nickel oxide," Thin Solid Films, vol. 355, pp. 26-34, 1999.

[5] I. Bedja, S. Hotchandani, R. Carpentier, K. Vinodgopal, and P. V. Kamat, "Electrochromic and photoelectrochemical behavior of thin $\mathrm{WO}_{3}$ films prepared from quantized colloidal particles," Thin Solid Films, vol. 247, no. 2, pp. 195-200, 1994.

[6] C. W. Lai and S. Sreekantan, "Fabrication of $\mathrm{WO}_{3}$ nanostructures by anodization method for visible-light driven water splitting and photodegradation of methyl orange," Materials Science in Semiconductor Processing, vol. 16, no. 2, pp. 303-310, 2012.

[7] A. Watcharenwong, W. Chanmanee, N. R. de Tacconi, C. R. Chenthamarakshan, P. Kajitvichyanukul, and K. Rajeshwar, "Anodic growth of nanoporous $\mathrm{WO}_{3}$ films: morphology, photoelectrochemical response and photocatalytic activity for methylene blue and hexavalent chrome conversion," Journal of Electroanalytical Chemistry, vol. 612, no. 1, pp. 112-120, 2008.

[8] X. Zhang, K. Huo, L. Huo, L. Hu, and P. K. Chu, "Fabrication and photocatalytic activity of nanoporous $\mathrm{WO}_{3}$ film," Nanoscience and Nanotechnology Letters, vol. 2, no. 1, pp. 51-57, 2010.

[9] W. Li, J. Li, X. Wang, S. Luo, J. Xiao, and Q. Chen, "Visible light photoelectrochemical responsiveness of self-organized nanoporous $\mathrm{WO}_{3}$ films," Electrochimica Acta, vol. 56, no. 1, pp. 620-625, 2010.

[10] S. Berger, H. Tsuchiya, A. Ghicov, and P. Schmuki, "High photocurrent conversion efficiency in self-organized porous $\mathrm{WO}_{3}$," Applied Physics Letters, vol. 88, no. 20, Article ID 203119, 2006.

[11] C. G. Granqvist, "Electrochromic tungsten oxide films: review of progress 1993-1998," Solar Energy Materials and Solar Cells, vol. 60, no. 3, pp. 201-262, 2000.

[12] V. Cristino, S. Caramori, R. Argazzi, L. Meda, G. L. Marra, and C. A. Bignozzi, "Efficient photoelectrochemical water splitting by anodically grown $\mathrm{WO}_{3}$ electrodes," Langmuir, vol. 27, no. 11, pp. 7276-7284, 2011.

[13] Y. Nah, A. Ghicov, D. Kim, and P. Schmuki, "Enhanced electrochromic properties of self-organized nanoporous $\mathrm{WO}_{3}$," Electrochemistry Communications, vol. 10, no. 11, pp. 1777-1780, 2008.

[14] C. W. Lai, S. B. A. Hamid, and S. Sreekantan, "A novel solar driven photocatalyst: well-aligned anodic $\mathrm{WO}_{3}$ nanotubes," International Journal of Photoenergy, vol. 2013, Article ID 745301, 6 pages, 2013.

[15] C. W. Lai, S. Sreekantan, and Z. Lockman, "Photoelectrochemical behaviour of uniform growth $\mathrm{TiO}_{2}$ nanotubes via bubble blowing synthesised in ethylene glycol with hydrogen peroxide," Journal of Nanoscience and Nanotechnology, vol. 12, no. 5, pp. 4057-4066, 2012.

[16] C. W. Lai, S. Sreekantan, and J. Nanomater, "Effect of applied potential on the formation of self-organized $\mathrm{TiO}_{2}$ nanotube 
arrays and its photoelectrochemical response," Journal of Nanomaterials, vol. 2011, Article ID 142463, 7 pages, 2011.

[17] Y. C. Nah, I. Paramasivam, and P. Schmuki, "Doped $\mathrm{TiO}_{2}$ and $\mathrm{TiO}_{2}$ nanotubes: synthesis and applications," ChemPhysChem, vol. 11, no. 13, pp. 2698-2713, 2010.

[18] Z. Su and W. Zhou, "Formation, morphology control and applications of anodic $\mathrm{TiO}_{2}$ nanotube arrays," Journal of Materials Chemistry, vol. 21, pp. 8955-8970, 2011.

[19] D. Y. C. Leung, X. L. Fu, C. F. Wang et al., "Hydrogen production over titania-based photocatalysts," ChemSusChem, vol. 3, no. 6, pp. 681-694, 2010.

[20] C. W. Lai and S. Sreekantan, "Study of $\mathrm{WO}_{3}$ incorporated C$\mathrm{TiO}_{2}$ nanotubes for efficient visible light driven water splitting performance," Journal of Alloys and Compounds, vol. 547, pp. 43-50, 2013. 


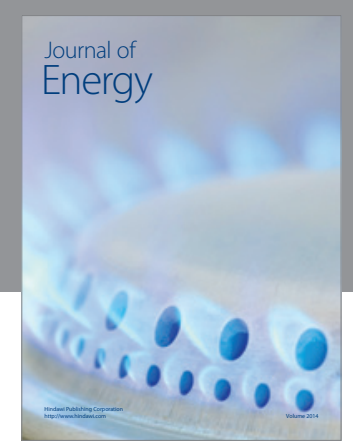

Journal of

Industrial Engineering
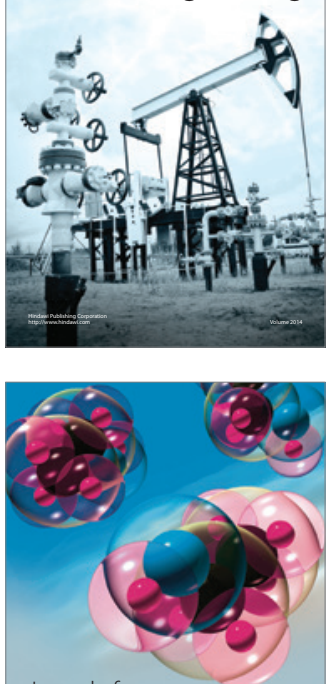

Fuels
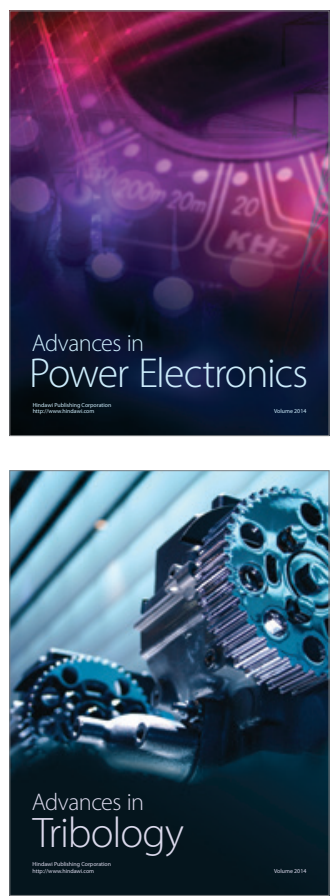

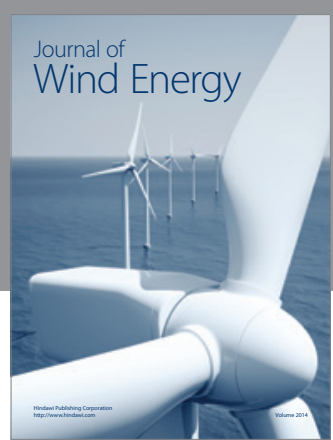

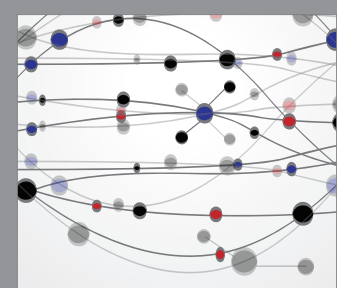

The Scientific World Journal

Submit your manuscripts at http://www.hindawi.com

Journal of

Structures
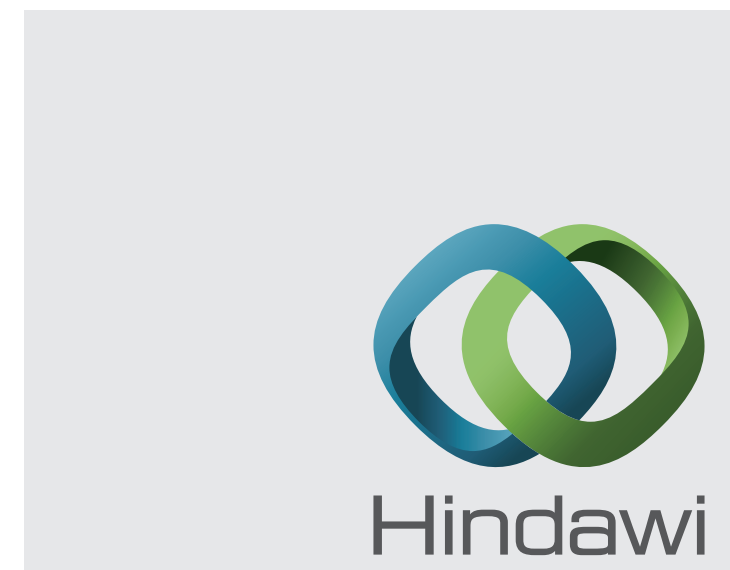

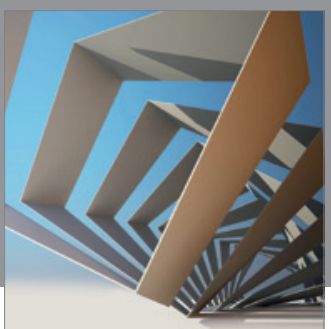

Rotating

Machinery
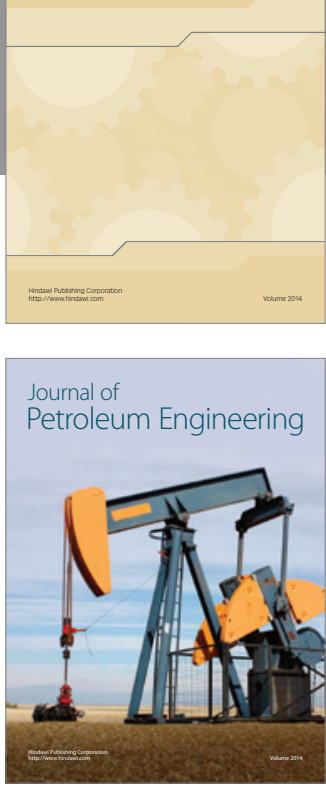

Journal of

Solar Energy
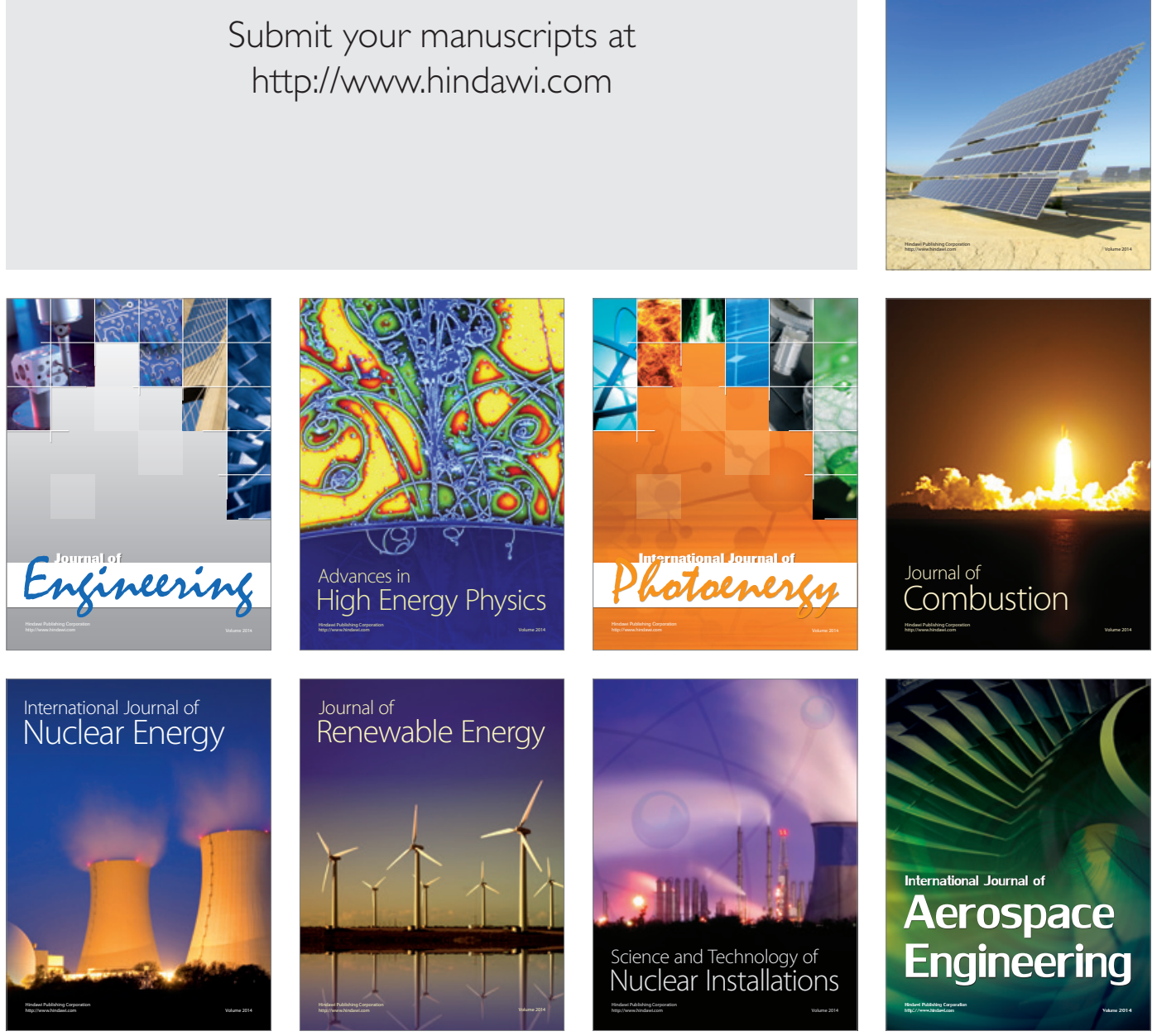